\title{
Experiences and perceptions of Return to Work (RTW) by clients with major depressive disorder in an extended sick leave period
}

\author{
Lebohang Saonatse, BSc OT (UCT); MSc OT (Wits) https://orcid.org/0000-000 I-88 I 2-7564 \\ Senior Therapist, Chris Hani Baragwanath Hospital, Johannesburg. Post graduate student, Department of OT, School of Theraputic \\ Sciences, Faculty of Health Sciences, University of the Witwatersrand.
}

Patricia Ann De Witt, Nat Dip OT (Pretoria); MSc OT (Wits); PhD (Wits) https://orcid.org/0000-0003-36 I2-0920 Sessional Senior Lecturer, Department of Occupational Therapy, School of Therapeutic Sciences, University of the Witwatersrand

Matty van Niekerk, B Proc (UFS), B OT (UP), MSc Dip Voc Rehab (UP), MSc (Bioethics and Health Law) (Wits) https://orcid.org/0000-000I-7505-5709

Lecturer, Department of Occupational Therapy, School of Therapeutic Sciences, University of the Witwatersrand

Introduction: Major Depressive Disorder (MDD) may cause difficulties that can influence employment. Although clients with MDD are typically expected to return to work (RTW) early, most are given the maximum duration of sick leave subsidised by their medical aid scheme, to recover. This study explored the lived perceptions and experiences of clients with MDD whilst on extended sick leave.

Methods: The study used a descriptive phenomenological qualitative study design. Data were collected through informant interviews. An inductive content analysis was used to analyse the data.

Findings: Eight participants were included in the study, of which $75 \%(n=6)$ were females and $25 \%(n=2)$ were males. One theme emerged from the data, namely 'waiting to RTW' with three categories (I) 'ruminating about RTW', (2) 'fears about RTW' and (3) 'social pressures to RTW'.

Conclusion: The period of waiting to RTW after hospitalisation was found to be stressful due to perceived work issues and rumination about work politics that were perceived to contribute to the illness. However, social pressures also play a vital role as a facilitator to RTW. These findings have implications for vocational preparation by occupational therapists during this extended sick leave period.

Key words: Major Depressive Disorder, Perceptions, Experiences, Return to Work

\section{INTRODUCTION}

In South Africa, mental health care is provided to the 56.52 million citizens by both a private health sector that services approximately $16 \%$ of the more affluent population, while the public sector serves the remaining citizens'. The private health sector is funded by medical aid schemes, and members buy into a scheme that provides a managed medical health care package. Thus, clients diagnosed with a mental illness are typically admitted to a private hospital for a maximum of 21 days according to the Prescribed Minimum Benefits (PMB) as set out by the medical aid scheme. During the early stage of admission, clients are commonly acutely ill and the intervention focus is on ensuring medical stability. However, the 2I-day period of hospitalisation seldom allows clients with Major Depressive Disorder (MDD) to recover fully and they are typically discharged with residual symptoms, which vary in severity. Additionally, inadequate time is spent on rehabilitation which fails to address factors that may facilitate or challenge successful return to work (RTW). Due to the presence of residual symptoms, the consulting psychiatrists usually recommend that employed clients be given additional sick leave whilst they are monitored as outpatients. The medical aid schemes allow for very little rehabilitation during extended sick leave periods and therefore, gains made in the in-patient RTW programme are frequently lost within this extended period prior to RTW, which clients have reported to be anxiety producing and stressful.

As an employee at a private psychiatric clinic in Soweto, Johannesburg, this was also the experience of the first author. The clinic provides services to citizens of middle-income status which enables them to belong to medical aid schemes. Of greatest concern were clients with MDD where the onset of the illness is usually between 20 and 30 years ${ }^{2}$. MDD impacts the work career of these individuals at different times, frequently at the beginning of their working life cycle due to the early onset and also hinders work progression in the longer term ${ }^{3}$. Due to the associated high disability prevalence such as poor functioning in activities of daily living and frequently reported difficulties with employment, clients diagnosed with MDD are unsure if and when they should return to work following an admission for hospital care ${ }^{4-6}$.

While international literature recommends early RTW after a hospital admission for MDD, little is known about the perceptions and experiences of clients regarding factors influencing early or delayed RTW ${ }^{7}$ in the South African context.

This study therefore aimed to explore the lived perceptions and experiences of RTW of clients with MDD after an extended sick leave period and subsequently, how the in-patient RTW programme needed to be adjusted and alternative rehabilitation strategies explored to enable the outcome of a successful RTW. This article reports on the exploration of the lived experiences of clients with MDD in relation to delayed RTW, and factors perceived to influence RTW.

\section{LITERATURE REVIEW}

Mental illnesses contribute to the global burden of disease and are reported to affect $10 \%$ of the global adult population ${ }^{7,8}$. Despite this, relatively few studies have been reported on this topic in developing countries such as South Africa, ${ }^{9}$. This indicates a gap in the knowledge about how mental illness is viewed in African countries and particularly how clients perceive and experience mental illness in relation to their state of employment mainly because the majority of literature described mental illness from Western perspectives. However, there are African concepts and understandings of mental 
illnesses which are defined by different communities or groups and it is therefore common that some of the communities still do not accept the western concepts of mental illness. They rather use their own understanding of mental illness to explain the strange behaviours that fall outside the social norms of the Western context.

Major depressive disorder (MDD) is one such illness. It has recently been reported that MDD affects about $5 \%-10 \%$ of the world's population ${ }^{8}$. The lifetime prevalence of MDD is estimated at $9.8 \%$ in South Africal'; with $18.3 \%$ of the South African population receiving treatment for depression at any given time ${ }^{12}$. The typical onset of MDD is between 20 and $30^{2}$ with an average age of onset at 26 years in South Africa " which usually coincides with the beginning stages of a person's working life ${ }^{3}$. Thus, while MDD is a condition that affects participation in most areas of occupation, it has significant impact on work performance ${ }^{13,14}$ and is frequently associated with poor work performance and disability ${ }^{15}$. The nature of MDD is that the episodes are usually prolonged and that it may progress to being chronic with high incidences of a relapse and thus may be recurrent ${ }^{16}$.

Over time, the meaning and purpose of work has evolved, however the worker role has always been important in determining an individual's socio-economic and social status ${ }^{17}$. The resumption of work by people with mental illness has been associated with "recovery" (despite the presence of residual symptoms ${ }^{18}$ ) and MDD is one such illness. However, literature reports that clients with MDD frequently wish to stay away from the workplace for a longer time than is necessary, due to fears of dealing with stigma from colleagues and self-pity, thus increasing the risk of isolation ${ }^{19}$. Due to the impairing and disabling nature of $\mathrm{MDD}^{20}$, clients experience varying degrees of limitations in the recognised occupational performance areas and dysfunction in performance skills, including poor socialisation, restricted participation in important activities of daily living, as well as decreased efficiency and effectiveness at work $^{21}$. Return to work in good health is an important functional outcome for clients with MDD, but this may be affected by several factors such as the client's motivation, support from the family and colleagues, work demands and work policies.

Literature emphasises the importance of clients diagnosed with MDD receiving adequate intervention not only at times of acute illness but also post-discharge to manage and reduce acute exacerbation of episodes and hospitalisation. Liberman et al. ${ }^{22}$ states that the rehabilitation of clients with MDD consists of a comprehensive intervention carried out by different health professionals occurring simultaneously. Occupational therapy is one such profession that can positively contribute to the recovery of clients with MDD. Return to work is highlighted as an important outcome of treatment, since the long-term effects of absenteeism from work is not only personally disabling but is also a burden to the economy ${ }^{23}$. The inclusion of occupational therapy in the treatment of MDD improves the treatment outcomes by influencing the overall functioning of the client, particularly in the occupational performance areas which have been affected by MDD, but especially $R T W^{18}$.

\section{RESEARCH METHODOLOGY}

A qualitative method of inquiry was used to explore the complexities and challenges of RTW from the client's perspectives during the period following discharge, but before RTW. A descriptive phenomenological approach was selected to describe and interpret the meaning and understanding of waiting to RTW from the clients' perspective ${ }^{24}$. The participants' experience was assumed to be known only by them ${ }^{25}$, thus adding valuable and meaningful information that could inform intervention in the future.

\section{Study Population}

The study population included clients diagnosed with MDD who were employed and who had had an admission to a private psychiatric hospital in Soweto.

The clients invited to participate in the study met the following inclusion criteria: They were under the retirement age; had a diagnosis of MDD confirmed by a registered psychiatrist using the Diagnostic and Statistical Manual of Mental Disorders Fifth Edition (DSM 5) classification; were permanently employed in a public or private organisation and not self-employed; had to have attended an occupational therapy vocational rehabilitation programme whilst admitted to the hospital and had attended their follow-up outpatient sessions with the psychiatrist.

Expert purposive sampling was used by the researcher to select clients that met the inclusion criteria where the clients with MDD were considered the experts in this process ${ }^{26,27}$. Potential participants who met the inclusion criteria were identified from the occupational therapy department records. They were invited to participate and on acceptance, were emailed the approved information sheet. The recruitment process took longer than expected due work commitments of the participants and potential participants being reluctant to take time off work to participate in the study, especially after a prolonged sick leave. Data were therefore collected over a six-month period. The study was approved by the Faculty of Health Science's Graduate Studies Committee and Medical Human Research Ethics Committee at the University of Witwatersrand (MI40968). The hospital manager also gave approval to conduct the study at the hospital. On agreeing to participate, participants were given two consent forms to sign: one to participate in the study and the other for audio-recordings of the interviews.

\section{Data collection}

The data were collected in key informant interviews, which were held at the participants' convenience once they had agreed to participate and the ethical procedures described above had been completed. The demographic data were collected using a selfreport questionnaire designed specifically for the study. The clients completed the questionnaire independently.

The qualitative data were collected in semi-structured interviews $^{28}$ that lasted approximately an hour. The researcher conducted all interviews. As the researcher had provided the RTW occupational therapy programme offered at the clinic in which all subjects had participated, she knew and had rapport with them. This also required that the researcher use bracketing before the interview to fully immerse herself in understanding the perceptions and experiences of participants and to ensure that no prior knowledge influenced her ability to understand the clients' perceptions and experiences ${ }^{29}$.

At the beginning of the data collection session, the researcher reaffirmed the purpose of the interview and gave the participants assurance that their participation was voluntary. Open-ended questions (see addendum) were used to guide the entire semi-structured interview. These were mostly predetermined and qualitative in nature to explore and understand the clients' perception and experiences of RTW in their pre-RTW period ${ }^{30}$. Discussion was not limited to these questions and participants were encouraged to express any thoughts and views they had on the topic.

To ensure that truthfulness and rigor were applied in this study, the researcher ensured that the criteria described by Guba and Lincoln ${ }^{31}$, were used. Member checking with the participants ${ }^{32}$ and peer review $w^{33}$ were also done to ensure credibility of the study.

\section{Data analysis}

The demographic data were analysed descriptively while the qualitative data were analysed manually using inductive content analysis, reported to be helpful in clinical health care research ${ }^{34,35}$. All interview audio-recordings were transcribed verbatim. The data analysis that followed was done in the three steps as described by Smoski et.al. ${ }^{36}$ : the first step involved reading the transcripts, identifying $5 \mathrm{I}$ significant words or statements that emerged as well as distinguishing between the participants' experiences and their perceptions. In the second step, the researcher identified the themes that emerged by identifying similar ideas or connections and attempted to make sense of these connections. The researcher then clustered the themes and matched them to extracts of what 
the participants had described. In the final step, the researcher created a table listing all themes, categories and codes that emerged from the data.

\section{FINDINGS}

\section{Participants}

Eight participants were included in the study. The period of sick leave prior to RTW ranging from two months to four months (average of 2.5 months).

The sample included $75 \%(n=6)$ females and $25 \%(n=2)$ males. The ages of participants ranged from 25-46 years and average age was 34.5 years. Only two of the participants were married, however five participants had children (between one and three children) but all participants had people at home for whom they were responsible and supported financially (See Table I below). The demographic results also indicate that all participants had completed secondary school and had obtained a national senior certificate. Seven of the eight participants had additional education ranging from a higher diploma to a bachelors level qualification. Those who had additional qualifications seem to have gained their first job earlier than one participant who only had a grade 12 education level. All participants worked in order to gain finances to care for significant others or improve their life. None of the participants were shift-workers however, the work hours per week of the participants ranged from 35 hours to 65 hours. Only two participants used their own cars to travel to work whilst the six other participants used public transport which included a taxi or a bus.

\section{Themes, categories and codes}

The only theme that emerged to be reported in this article was waiting to return to work. The categories and codes arising from this theme can be seen in Table II.

This theme described the perceptions and experiences of clients whilst they were waiting to return to work. The word "waiting" described what the clients were doing and feeling prior to RTW.
Table II: Theme, categories and codes

\begin{tabular}{|l|l|l|}
\hline \multirow{4}{*}{ Waiting to RTW } & CATEGORIES & CODES \\
\cline { 2 - 3 } & $\begin{array}{l}\text { Ruminating about } \\
\text { RTW }\end{array}$ & $\begin{array}{l}\text { Reluctance to RTW } \\
\text { Concerns about work } \\
\text { politics } \\
\text { Job contributing to illness }\end{array}$ \\
\cline { 2 - 3 } & Fears about RTW & $\begin{array}{l}\text { Chances of relapse } \\
\text { Not coping on RTW }\end{array}$ \\
\cline { 2 - 3 } & $\begin{array}{l}\text { Social pressure to } \\
\text { RTW }\end{array}$ & $\begin{array}{l}\text { Meeting financial needs and } \\
\text { responsibilities }\end{array}$ \\
\hline
\end{tabular}

As described above, medical schemes typically fund only a threeweek period of hospitalisation. Most of the participants had been admitted for the full period and had been prescribed an additional period of sick leave, as the psychiatrists were of the opinion that the participants were not yet ready to RTW. The additional sick leave was viewed by all participants as essential to their recovery. However, the participants indicated that during this period, while they were waiting to RTW, they felt troubled.

The weeks that I was at home, it was hard. I was always yawning. I was so tired. I was exhausted. I could not even drive, and I had things to do [but I could not do them]. I could not understand what was going on with me. I could not even sleep [P8].

This feeling of being troubled was linked to concerns about their job security due to them experiencing residual symptoms and side-effects from the medication, as well as the communication that they received from their managers, colleagues and human resource personnel, questioning the duration of their sick leave and demanding to know when they would RTW. Here the participant reports feeling tired but despite the physical exhaustion, the participant struggled to sleep. Which may have been contributed to by being worried about their job security. It also emerged that the only communication that participants received was regarding

Table I: Demographic characteristics of the participants / Participant's educational and vocational information $(n=8)$

\begin{tabular}{|c|c|c|c|c|c|c|c|c|c|c|c|c|}
\hline $\begin{array}{l}\text { Partici- } \\
\text { pants }\end{array}$ & $\begin{array}{c}\text { Age } \\
\text { (years) }\end{array}$ & Gender & $\begin{array}{c}\text { Marital } \\
\text { status } \\
(\text { Married = M, } \\
\text { Single = S) }\end{array}$ & Children & $\begin{array}{l}\text { People } \\
\text { in house }\end{array}$ & $\begin{array}{c}\text { RTW } \\
(\mathbf{Y e s}=\mathbf{Y}, \\
\text { No=N) }\end{array}$ & $\begin{array}{c}\text { Tertiary } \\
\text { qualifica- } \\
\text { tions }\end{array}$ & $\begin{array}{l}\text { Age of } \\
\text { first job } \\
\text { (year)s }\end{array}$ & $\begin{array}{l}\text { Type of } \\
\text { work }\end{array}$ & $\begin{array}{l}\text { Distance } \\
\text { to work }\end{array}$ & $\begin{array}{c}\text { Working } \\
\text { hours } \\
\text { (hrs) }\end{array}$ & $\begin{array}{c}\text { Reason for } \\
\text { working }\end{array}$ \\
\hline I & 26 & $\mathrm{~F}$ & $S$ & I & Fiancé & $\mathbf{Y}$ & $\begin{array}{l}\text { Higher } \\
\text { certificate }\end{array}$ & 20 & $\begin{array}{l}\text { Service } \\
\text { agent }\end{array}$ & $33 \mathrm{~km}$ & $37.5 \mathrm{hrs}$ & $\begin{array}{l}\text { "Provide for } \\
\text { family" }\end{array}$ \\
\hline 2 & 27 & $\mathrm{~F}$ & $S$ & I & $\begin{array}{l}\text { Grand- } \\
\text { mother } \\
\text { and son }\end{array}$ & $\mathbf{Y}$ & $\begin{array}{l}\text { Higher } \\
\text { certificate }\end{array}$ & 21 & $\begin{array}{l}\text { Office } \\
\text { adminis- } \\
\text { tration }\end{array}$ & $13 \mathrm{~km}$ & $35 \mathrm{hrs}$ & $\begin{array}{l}\text { "To make a } \\
\text { living” }\end{array}$ \\
\hline 3 & 37 & $M$ & $M$ & 3 & $\begin{array}{l}\text { Wife and } \\
\text { children }\end{array}$ & $\mathbf{Y}$ & Diploma & 20 & $\begin{array}{c}\text { DTP } \\
\text { operator }\end{array}$ & $45 \mathrm{~km}$ & $45 \mathrm{hrs}$ & $\begin{array}{l}\text { "To look after } \\
\text { my family and } \\
\text { extended } \\
\text { family" }\end{array}$ \\
\hline 4 & 44 & $\mathrm{~F}$ & $M$ & 2 & $\begin{array}{l}\text { Husband } \\
\text { and } \\
\text { children }\end{array}$ & $\mathbf{Y}$ & $\begin{array}{l}\text { Higher } \\
\text { certificate }\end{array}$ & 22 & $\begin{array}{c}\text { Data } \\
\text { capturer }\end{array}$ & $5 \mathrm{~km}$ & $40 \mathrm{hrs}$ & $\begin{array}{l}\text { "To support } \\
\text { the family" }\end{array}$ \\
\hline 5 & 32 & $M$ & $\mathrm{~S}$ & 0 & Fiancé & $\mathbf{Y}$ & Diploma & 21 & $\begin{array}{l}\text { IT spe- } \\
\text { cialist }\end{array}$ & $45 \mathrm{~km}$ & $45 \mathrm{hrs}$ & $\begin{array}{l}\text { "Making a } \\
\text { living" }\end{array}$ \\
\hline 6 & 39 & $F$ & $S$ & 2 & $\begin{array}{l}\text { Mother, } \\
\text { children } \\
\text { and } \\
\text { brothers }\end{array}$ & $\mathbf{Y}$ & $\begin{array}{l}\text { Higher } \\
\text { certificate }\end{array}$ & 20 & $\begin{array}{l}\text { Office } \\
\text { adminis- } \\
\text { tration }\end{array}$ & $24 \mathrm{~km}$ & $50 \mathrm{hrs}$ & $\begin{array}{c}\text { "Making a } \\
\text { living, taking } \\
\text { care of family, } \\
\text { having a better } \\
\text { life" }\end{array}$ \\
\hline 7 & 46 & $\mathrm{~F}$ & $\mathrm{~S}$ & 0 & $\begin{array}{l}\text { Mother } \\
\text { and sister }\end{array}$ & $\mathbf{N}$ & None & 32 & $\begin{array}{l}\text { Service } \\
\text { consul- } \\
\text { tant }\end{array}$ & $20 \mathrm{~km}$ & $40 \mathrm{hrs}$ & $\begin{array}{l}\text { "To support } \\
\text { mom" }\end{array}$ \\
\hline 8 & 25 & $\mathrm{~F}$ & $\mathrm{~S}$ & 0 & $\begin{array}{l}\text { Grand- } \\
\text { parents } \\
\text { and } \\
\text { brother }\end{array}$ & $\mathbf{N}$ & B Tech & 22 & $\begin{array}{l}\text { Site engi- } \\
\text { neer }\end{array}$ & $58 \mathrm{~km}$ & $65 \mathrm{hrs}$ & $\begin{array}{c}\text { "Double shifts } \\
\text { and supervi- } \\
\text { sion" }\end{array}$ \\
\hline
\end{tabular}


the time for return to work, which also contributed to the sense of worrying and being troubled. One of the participants reported:

Well, ok, they phoned me. I remember when they told me that I had to come back to work [now]. [P7]

As can be seen from Table II on page 38, three categories were identified within this theme, and these are (I) ruminating about RTW, (2) fears about RTW and (3) pressure to RTW.

\section{Category I: Ruminating about return to work}

The nature of MDD is that it perpetuates negative thoughts especially when issues have not been adequately resolved ${ }^{37}$. These negative thoughts encouraged the client to continuously and unconstructively brood on and agonise over issues that bother them. The participants reported many issues that were still bothering them, but commonly participants were brooding on unresolved work issues and the contribution that work had made to the development of their illness. The quote below is typical of what the participants were thinking about during their sick leave.

To a big extent, [work contributed to illness] especially my recent position now. Because the pressure is too high. The workload is too much. The expectations, obviously from the powers that be and also I don't want to call it passing the bar [buck], but I want to say that some of the admin ladies that are there, I have assumed their roles. [P6]

Participants were also preoccupied about their imminent RTW and these thoughts were mostly negative as some of them included work politics experienced.

I think a lot ...about [work], mostly about bad things and not good things. Both the work and the pressure. If it was the work alone it was fine because I would find ways to deal with it. But when there is someone [manager] involved in putting too much pressure on you, you end up not knowing what to do. [P2]

I was thinking about so many things, like killing myself or just disappearing. There are so many challenges [at work] [despite this] I really like my work. [P7]

There is a lot of nepotism at work I was the only person that got there [got appointed] without knowing someone or having worked with anyone else within our division. So everyone is someone's cousin, it just does not work honestly. [P8]

\section{Category 2: Fear about return to work}

The experience of fear amongst the participants was described in the second category of this theme. Fear mostly related to job security, the period of absence and uncertainty about what would happen upon RTW.

The psychiatrists only informed employers about the recommended additional sick leave and its duration after the participants were discharged from the hospital, which averaged 2.5 months. All the participants were entitled to a three-year leave cycle of 30 or 36 days, depending on whether they have a 5- or 6-day workweek. However, due to the nature of MDD, the participants experienced symptoms long before the diagnosis was made and had considerable time away from work even before their hospital admission.

While the long sick leave can be advantageous to their recovery, it can also cause the participants to develop serious concerns about their job security, as well the fear of not knowing what to expect when they RTW as the work issues experienced prior to admission had not yet been addressed or resolved.

I suppose also the fear of not knowing how the division works in terms of people being away for months, for so long and what their HR requirements are. If they would actually have a welcoming environment for me when I returned. [P6]

Actually, I did not have any expectations but my fear was that I had to go back to work....nothing has been done [during the time I was sick]. [P4]

So I was worried [about] how was I going to cope with the system, looking at the computer for more than four hours every day. [P4]
Firstly, it appeared that the participants were not aware of their conditions of service especially when it came to long sick leave. Secondly, the participants did not appear to communicate with their HR representatives regarding the conditions of sick leave, thus perpetuating concern about their sick leave, which could have been avoided.

\section{Category 3: Social pressures associated with RTW}

The final category in this theme concerns the social pressure to RTW. This was of particular interest as the participants had all experienced negative thoughts about RTW expressing that they did not want to RTW however, they reported that they felt pressured to RTW.

\section{So I just had to [return to work]. [P2]}

Financial concerns was the single code identified. It was clear from the demographic information that all the participants had financial responsibilities to fulfil and had family members or significant others to take care of. Financial independence and being able to take care of one's needs was important to the participants. It was noted that this was a strong driver to RTW in spite of the participants' fears and misgivings about the job they held and the extent to which they felt it contributed to their illness:

Working is a big part of living and working is a big part of being able to be independent and not depend on other people to feed you, clothe you. [P6]

I had to work and make a living for my child [P2].

Honestly, firstly it was looking after my family. If I do not work, my family is going to suffer. [P3]

In summary, this theme highlighted both the participants' perception of RTW and their experiences of awaiting RTW. These were predominantly negative and it appeared that this period was very difficult for the participants.

\section{DISCUSSION}

In the extended sick leave period prior to RTW, all the participants reported experiencing a preoccupation regarding their workrelated stressors that may have contributed to their illness and their subsequent admission as persistent and distressing. The experience of constant negative thinking was consistent with rumination, described by Nolen-Hoeksema et al. ${ }^{38}$ as constant, ongoing and fixated negative thoughts, which may occur before or after being diagnosed. While rumination has been described as a common symptom associated with MDD, its persistence in the recovery period has been reported to slow progress and prolong the depressed mood.

\section{Rumination}

The process of rumination was reported to be centred on the unresolved work stressors leading to hospitalisation. This lived experience was consistent with a few other studies ${ }^{4,37,39}$ reporting that the experience of work stress could lead to admission. The experience of ongoing rumination was also a result of the participants - having limited coping skills - left the issues too late and did not consult a health care worker for assistance at an earlier stage ${ }^{39}$.

A common experience amongst all the participants was ruminating about the perceived work politics despite the different work environments. Although studies have not specifically researched rumination of work politics, a study by Lee et al. ${ }^{40}$ indicated a positive association between depression and work related stress. This was consistent with studies by Wiegner et al. ${ }^{41}$ and Khamisa et al. ${ }^{42}$ which described that the experience of burnout and stress leads to symptoms of depression in the workplace. The implication of the constant negative thinking had an impact on their lack of motivation to RTW, as reported as a lived experience by the participants of the current study. The other focus of the rumination experienced by the participants was the negative perceptions about their inability 
to cope with work, which they perceived as self-doubt and vulnerability in their job security.

\section{Extended sick leave}

The decision to delay RTW through an extended sick leave period was highlighted by participants as a concern. Health settings in different countries, particularly in developing countries, have their own processes in terms of RTW with regards to people with mental illness ${ }^{43}$. In the current study, neither the multidisciplinary team nor the participants were involved in the decision to RTW. The psychiatrist managing the case based on their medical clinical reasoning made this decision independently. The medical model approach to mental health care is still widely used in acute private health settings whereby the psychiatrist makes the final decision about the client's intervention and outcome thereof. This approach tends to exclude the client (despite the client being stable) and input from the multidisciplinary team (MDT). However, a client-centred model, which is more central to an occupational therapy philosophy, proposes that the client is a key role- player in the recovery process and thus needs to be involved in decision-making on their health and in case of RTW. The medical model approach apparent in this study, differed from studies reported in developed countries, where the treatment approach is more multi-disciplinary. In such cases the multidisciplinary team (MDT), consisting of a number of health care professionals with expert knowledge in different areas contributing to the overall health and wellbeing of the client, and the client (as a key role player), collaborates with the team on important client related decisions ${ }^{23}$. The team may include professionals such as occupational therapists, psychologists, social workers, case managers and the employer amongst others, to consider barriers and facilitators that may have an impact on RTW ${ }^{22}$ and to improve RTW success ${ }^{44}$

\section{Fear about return to work}

The participants in the current study reported experiencing considerable fear related to their condition and its impact on their life, which supports the findings of other studies ${ }^{45-47}$. The experience of fear as reported by participants was influenced by their perception of their illness and their experience of how their illness affected their daily functioning especially their work. All participants experienced it as distressing and incapacitating. This finding was consistent with a study by Wernicke et al. ${ }^{48}$, where the participants all reported the experience of their illness is distressing. However, this can also be associated with 'personal stigma' as the participants reported that they perceived their illness as a sign of weakness and failure. This finding is consistent with a study by Coppens, et al. ${ }^{49}$. When exploring the lived experience of fear, the participants mostly feared relapsing. The fear of relapsing was particularly associated with the participants who experienced their episode for the first time. Whilst still waiting to RTW, the participants also experienced fear of not coping with their work tasks upon returning to work. Again, the employers and mangers have little awareness of the implication of this condition on workers and their work output. Most importantly there are no laws (only guidelines) protecting clients with depression as many employers do not view MDD as a disability, which is defined in the Employment Equity Act no. 55 of 1998 under item 5.I as either a long standing or a recurring mental or physical impairment that hinders employability ${ }^{50}$. These lived experiences and perceptions are supported by a study by Mokoka, et al. ${ }^{51}$ that MDD is not considered a disability, as the client is expected to return to their premorbid functioning and to be involved in gainful employment.

\section{Pressure to return to work}

It was interesting that, despite both the challenges at work and the fear the participants experienced, most of the participants felt pressurised to RTW due to meeting financial needs and responsibilities. The South African leave incapacity policy, only allows an employee (depending on company policy) to receive $75 \%$ of their monthly salary when the sick leave cycle (36 days in a three-year cycle) has been exhausted. This subsequently affects the ability to pay off household costs and other debts, thus motivating the participants to RTW. Surprisingly, the financial pressure to RTW has been observed in participants with different types of mental illnesses including severe mental illnesses, as seen from a study that was done by Serowik, et al..$^{52}$, Ekberg et a ${ }^{43}$ and earlier by Kennedy et al. ${ }^{47}$, as well as a cancer study by Islam, et al. ${ }^{53}$. The participants that particularly experienced the financial pressure to RTW were the main breadwinners and for whom supporting their families was important and a major concern. This was consistent with the findings of the study by Islam et al. ${ }^{53}$.

\section{CONCLUSION}

This study identified that participants experienced the extended sick leave period after hospitalisation for MDD as distressing, although helpful to their recovery. Participants experienced the period of waiting to RTW after hospitalisation as stressful due to perceived work load and job content concerns as well as work politics that participants believed had contributed to their illness in the first place. In addition to the constant ruminations, the clients experienced pressure to RTW due to perceived social pressure in meeting their financial demands and responsibilities as breadwinners. Simultaneously, the clients also experienced fears about RTW, which included chances of relapsing and not coping on RTW. The facilitator of RTW for this unique population were positive attitude of the family and colleagues, and meeting their financial needs and responsibilities, whilst the barriers of RTW were the negative attitudes of colleagues, fear of chances of relapsing and/not coping and rumination about work.

From the results of this study it would appear that RTW issues for clients with MDD issues would be best addressed in an out-patient RTW programme rather than in an in-patient RTW programme within the $2 \mathrm{I}$ days of an admission when the client is still acutely ill. This programme should provide intervention to support strategic work preparation and supported employment to facilitate the transition back into the work place. The programme can also include stress management techniques and coping skills that the clients can employ when confronted by work challenges. Medical aids and structures within labour should be lobbied to provide funding for this type of rehabilitation as an extension to the PMB package essential for MDD and other mental illnesses that may affect work productivity. Major Depressive Disorders should also be handled the same way as when a worker is injured on duty, as most participants in this study reported that work played a major role in their diagnosis.

\section{ACKNOWLEDGEMENTS}

The authors would like to thank the participants who participated in the research study and expressed their lived perceptions and experiences of RTW and acknowledge funding received from the Research Endowment Grant, Faculty of Health Sciences, University of the Witwatersrand. The authors would also like to express gratitude from Dr Denise Franzsen for her expert advice and assistance. Many thanks to Zanodumo Banda for his encouragement.

\section{REFERENCES}

I. Statistics South Africa, Public healthcare: How much per person? Pretoria: Statistics South Africa; 2017.

2. Klein DN, Glenn CR, Kosty DB, et al. Predictors of first lifetime onset of major depressive disorder in young adulthood. Journal of Abnormal Psychology. 2013; I22: I. http://dx.doi.org/10.1037/a0029567

3. Patten SB, Wang JL, Williams JV, et al. Descriptive epidemiology of major depression in Canada. The Canadian Journal of Psychiatry. 2006; 5 I: 84-90. http://doi.org/10. I I77/07067. http://doi.org/10.1 I 77/070674371506000106.

4. Waghorn $\mathrm{G}$ and Lloyd $\mathrm{C}$. The employment of people with mental illness. Australian e-Journal for the Advancement of Mental Health. 2005; 4: I 29-I7I. http://dx.doi.org/I0.1002/978|4443 | 9736.

5. Judd LL, Schettler PJ, Solomon DA, et al. Psychosocial disability 
and work role function compared across the long-term course of bipolar I, bipolar II and unipolar major depressive disorders. Journal of Affective Disorders. 2008; 108: 49-58.

https://doi.org/10.1016/j.jad.2007.06.014.

6. Birnbaum HG, Kessler RC, Kelley D, et al. Employer burden of mild, moderate, and severe major depressive disorder: mental health services utilization and costs, and work performance. Depression and Anxiety. 2010; 27: 78-89. http://doi.org/10.1002/da.20580.

7. World Health Organization. The International Classification of Functioning, Disabiity and Health Framework (ICF). Geneva Switzerland: WHO; 2001 .

8. Amini K, Negarandeh R, Cheraghi MA, et al. Major depressive disorder: A qualitative study on the experiences of Iranian patients. Issues in Mental Health Nursing. 201 3; 34: 685-692. http://doi.org/10.3109/01612840.2013.789942.

9. Hugo CJ, Boshoff DE, Traut A, et al. Community attitudes toward and knowledge of mental illness in South Africa. Social Psychiatry and Psychiatric Epidemiology. 2003; 38: 715-719. https://doi.org/10.1007/s00 I 27-003-0695-3.

10. Waqas A, Zubair M, Ghulam H, et al. Public stigma associated with mental illnesses in Pakistani university students: a cross sectional survey. Peer]. 2014; 2: e698. https://dx.doi.org/10.7717\%2Fpeerj.698.

II. Tomlinson M, Grimsrud AT, Stein DJ, et al. The epidemiology of major depression in South Africa: results from the South African stress and health study. South African Medical Journal. 2009; 99: 367-373.

12. Stander MP, Korb FA, de Necker M, et al. Depression and the Impact on Productivity in the Workplace: Findings from a South African Survey on Depression in the Workplace. Journal of Depression and Anxiety. S 2016; 2: 1-8.

http://dx.doi.org/10.4I72/2 I67-1044.S2-012.

13. Mclntyre RS, Soczynska JZ, Woldeyohannes HO, et al. The impact of cognitive impairment on perceived workforce performance: results from the International Mood Disorders Collaborative Project. Comprehensive Psychiatry. 2015; 56: 279-282. http://doi.org/10.1016/j.comppsych.2014.08.05I.

14. Greenberg MT, Weissberg RP, O’brien MU, et al. Enhancing schoolbased prevention and youth development through coordinated social, emotional, and academic learning. American Psychologist. 2003; 58: 466. https://psycnet.apa.org/doi/I0.1037/0003-066X.58.6-7.466.

15. Kessler RC, Zhao S, Blazer DG, et al. Prevalence, correlates, and course of minor depression and major depression in the National Comorbidity Survey. Journal of Affective Disorders. 1997; 45: 19-30. https://doi.org/10.1016/S0165-0327(97)00056-6.

16. Young A. Recurrent unipolar depression requires prolonged treatment. The British Journal of Psychiatry. 200I; I 78: 294-295.

17. Blank AA, Harries $P$ and Reynolds F. 'Without occupation you don't exist': Occupational engagement and mental illness. Journal of Occupational Science. 2015; 22: 197-209. https://doi.org/10.1 192/bjp. I78.4.294.

18. Schene AH, Koeter MW, Kikkert MJ, et al. Adjuvant occupational therapy for work-related major depression works: randomized trial including economic evaluation. Psychological Medicine. 2007; 37: 351-362. https://doi.org/10.1017/S003329|706009366.

19. Bilsker D, Wiseman S and Gilbert M. Managing depression-related occupational disability: a pragmatic approach. The Canadian Journal of Psychiatry. 2006; 51 : 76-83. https://doi.org/10.1 I77/070674370605100203.

20. Korb F. Depression in the workplace: guest editorial. Mental Health Matters. 20I5; 2: I-3.

21. Duncan M, Crouch R and Alers V. Three approaches and processes in occupational therapy with mood disorders. Occupational therapy in psychiatry and mental health. London: Whurr; 2005: 464.

22. Liberman RP, Hilty DM, Drake RE, et al. Requirements for multidisciplinary teamwork in psychiatric rehabilitation. Psychiatric Services. 2001; 52: |331-|342. https://doi.org/I0.|176/appi.ps.52.10.1331.

23. Millward L, Lutte $A$ and Purvis R. Depression and the perpetuation of an incapacitated identity as an inhibitor of return to work. Journal of Psychiatric and Mental Health Nursing. 2005; I2: 565-573. http://doi.org/ I0. I I I I/j. I365-2850.2005.00875.x.

24. Creswell J. Qualitative inquiry and research design: Choosing among five approaches. Los Angeles, CA: SAGE Publications; 2013.
25. Taylor RR. Kielhofner's Research in Occupational Therapy: Methods of inquiry for enhancing practice. FA Davis; 2017.

26. De Vos A, Strydom H, Fouche C, et al. Research at grass roots. Pretoria: Van Schaik; 2002.

27. Etikan I, Musa SA and Alkassim RS. Comparison of convenience sampling and purposive sampling. American Journal of Theoretical and Applied Statistics. 2016; 5: I-4. http://doi.org/10.1 I648/j.ajtas.2016050 I.I I.

28. Brink $H$, Van der Walt $C$ and Van Rensburg $G$. Fundamentals of research methodology for health care professionals. Juta and Company Ltd; 2006.

29. Elliott R, Fischer CT and Rennie DL. Evolving guidelines for publication of qualitative research studies in psychology and related fields. British Journal of Clinical Psychology. 1999; 38: 21 5-229. http://doi.org//0.1348/014466599162782.

30. Henning E, Van Rensburg W and Smit B. Finding your way in qualitative research. van Schaik Pretoria, 2004.

31. Guba EG and Lincoln YS. Fourth generation evaluation. Sage, 1989.

32. Creswell JW and Miller DL. Determining validity in qualitative inquiry. Theory into Practice. 2000; 39: I24-I30. https://doi.org//0.1207/s I543042 I tip3903_2.

33. Tuckett AG. Applying thematic analysis theory to practice: a researcher's experience. Contemporary Nurse. 2005; 19: 75-87. https://doi.org/10.5172/conu.19.1-2.75.

34. Bradley EH, Curry LA and Devers KJ. Qualitative data analysis for health services research: developing taxonomy, themes, and theory. Health Services Research. 2007; 42: I758- 1772. https://doi.org/10.5172/conu.19.1-2.75.

35. Elo $S$ and Kyngäs $H$. The qualitative content analysis process. Journal of Advanced Nursing. 2008; 62: 107-I I 5. http://doi.org/ I0. I I I I/j. I 365-2648.2007.04569.x.

36. Smoski MJ, Keng S-L, Ji JL, et al. Neural indicators of emotion regulation via acceptance vs reappraisal in remitted major depressive disorder. Social Cognitive and Affective Neuroscience. 2015; 10: I I87-I I 94. http://doi.org/I0.1093/scan/nsv003.

37. Kassam A and Patten SB. Major depression, fibromyalgia and labour force participation: a population-based cross-sectional study. BMC Musculoskeletal Disorders. 2006; 7: 4. http://doi.org/I0.1 I86/I47I-2474-7-4.

38. Nolen-Hoeksema S, Morrow J and Fredrickson BL. Response styles and the duration of episodes of depressed mood. Journal of Abnormal Psychology. 1993; 102: 20. http://dx.doi.org/10.1037/002I-843X.102.I.20.

39. Simpson G, Byrne P, Gabbay M, et al. Understanding illness experiences of employees with common mental health disorders. Occupational Medicine. 20I5; 65: 367-372. http://doi.org/10.1093/occmed/kqv047.

40. Lee JS, Joo EJ and Choi KS. Perceived stress and self-esteem mediate the effects of work-related stress on depression. Stress and Health. 20। 3; 29: 75-8I. http://doi.org. I0.1002/smi.2428.

4I. Wiegner L, Hange D, Björkelund C, et al. Prevalence of perceived stress and associations to symptoms of exhaustion, depression and anxiety in a working age population seeking primary care--an observational study. BMC Family Practice. 2015; 16. https://doi.org//0. I |86/s | 2875-0252.

42. Khamisa N, Oldenburg B, Peltzer $\mathrm{K}$, et al. Work related stress, burnout, job satisfaction and general health of nurses. International Journal of Environmental Research And Public Health. 2015; 12 : 652-666 http://doi.org/I0.3390/ijerph I 20100652

43. Ekberg K, Wåhlin C, Persson J, et al. Early and late return to work after sick leave: predictors in a cohort of sick-listed individuals with common mental disorders. Journal of Occupational Rehabilitation. 2015; 25: 627-637. http://doi.org/10.1007/s 10926-015-9570-9.

44. Hoefsmit N, Houkes I and Nijhuis FJ. Intervention characteristics that facilitate return to work after sickness absence: a systematic literature review. Journal of Occupational Rehabilitation. 2012; 22: 462-477. http://doi.org/10.1007/s 10926-012-9359-z.

45. Birchwood M, Smith J, Macmillan F, et al. Predicting relapse in schizophrenia: the development and implementation of an early signs monitoring system using patients and families as observers, a preliminary investigation. Psychological Medicine. 1989; 19: 649656. https://doi.org/10.1017/S0033291700024247.

46. Keough JL and Fisher TF. Occupational-psychosocial perceptions in- 
fluencing return to work and functional performance of injured workers. Work. 200 I; I6: I0I-I I0. http://doi.og/ I0. I I86/ I47I.2474-8-6.

47. Kennedy N, Foy K, Sherazi R, et al. Long-term social functioning after depression treated by psychiatrists: a review. Bipolar Disorders. 2007; 9: 25-37. https:/doi.org//0.1 I II/j. I399-56/8.2007.00326.x.

48. Wernicke RA, Pearlman MY, Thorndike FP, et al. Perceptions of depression among recovered-depressed and never-depressed individuals. Journal of Clinical Psychology. 2006; 62: 77I-776. https://dx.doi.org//0.1002\%2Fjclp.2026I.

49. Coppens E, Van Audenhove C, Scheerder G, et al. Public attitudes toward depression and help-seeking in four European countries baseline survey prior to the OSPI-Europe intervention. Journal of Affective Disorders. 2013; 150: 320-329. http://doi.org/10.1016/j. jad.2013.04.013.

50. Republic of South Africa. Employment Equity Act, No. 55 of 1998. Government Gazette. 1998; 400.

5I. Mokoka MT, Rataemane ST and Dos Santos M. Disability claims on psychiatric grounds in the South African context: A review. South African Journal of Psychiatry. 20I2; 18: 34-4I.

https://doi.org/I0.4102/sajpsychiatry.v I 8i2.290.

52. Serowik KL, Rowe M, Black AC, et al. Financial motivation to work among people with psychiatric disorders. Journal of Mental Health 20I4; 23: I 86-190. http://doi.org/I0.3 I09/09638237.20I4.924046.

53. Islam T, Dahlui M, Majid HA, et al. Factors associated with return to work of breast cancer survivors: a systematic review. In: BMC Public Health. 20I4, p.S8. http://do.org/i I0. I I86/I47I-2458-I4-S3-S8.

\section{Corresponding author}

Matty van Niekerk

matty.vanniekerk@wits.ac.za

\section{ADDENDUM}

\section{Interview Schedules}

\section{Clients that have returned to work}

I. Tell me more about your job or what you do at work

2. Do you think that your job may have contributed to your illness?

3. How do you feel about being diagnosed with MDD?

4. Tell me about your first day when you went to work after discharge

5. What motivated you to return to work after your sick leave?

6. What were your challenges or fears when you returned to work?

7. What discouraged you when you had to go back to work?

8. How were your colleague's behaviour? How was your supervisors' behaviour towards you?

9. How did you find the physical work environment?

10. How did you experience your job tasks?

II. What helped you to perform your job tasks as expected?

12. What were your main expectations?

\section{Clients that have not returned to work}

I. Tell me more about your job or what you do at work

2. Do you think that your job may have contributed to your illness?

3. How do you feel about being diagnosed with MDD?

4. How does it feel being on a long sick leave?

5. What kind of support are you receiving from work?

6. How does your family treat you now that you are at home?

7. How has your income being affected?

8. How has your confidence and self-esteem been affected by the long sick leave? 